Sousa MFB, Santos RL, Turró-Garriga O, Dourado MCN, Conde-Sala JL. Clinical factorial distribution of Anosognosia Questionnaire for Dementia (AQ-D) in a sample of patients with Alzheimer's disease. International Journal of Geriatric Psychiatry, 2016; 31 (11): 1252-1254. doi: 10.1002/gps.4473

\title{
Clinical factorial distribution of Anosognosia Questionnaire for Dementia (AQ-D) in a sample of patients with Alzheimer's disease
}

Authors: Maria Fernanda B. Sousa ${ }^{1 *}$, Raquel L. Santos ${ }^{1}$, Oriol Turró-Garriga ${ }^{2}$, Marcia C. N. Dourado $^{1}$, Josep L. Conde-Sala ${ }^{3}$

\section{Institutional affiliations:}

${ }^{1}$ Center for Alzheimer's Disease, Institute of Psychiatry, Universidade Federal do Rio de Janeiro, Rio de Janeiro, Brazil

${ }^{2}$ Dementia Registry, Aging, disability and health group of the Biomedical Research Institute of Girona - Institut d’Assistència Sanitària, Salt., Spain

${ }^{3}$ Faculty of Psychology, University of Barcelona, Barcelona, Spain

*E-mail: maria_fernandabs@yahoo.com.br 


\section{Introduction}

Patients with anosognosia have been presented more dangerous behaviours and difficulties with treatment adherence, leading to increased burden on caregivers (Conde-Sala et al., 2015). Anosognosia Questionnaire for Dementia (AQ-D; Migliorelli et al., 1995) has been used to collect patients and caregivers' perceptions about anosognosia. A factor analysis of the AQ-D produced two factors: lack of awareness of cognitive deficits and behavioural symptoms (Starkstein et al., 2006). However, when we considered Alzheimer's disease (AD) diagnostic criteria from American Psychiatric Association, whose principal aspects are cognition, functionality and behaviour/personality; those two factors proposed may not be enough to analyse anosognosia.

We investigated the factorial structure of the AQ-D from a clinical perspective. Specifically, the objectives were to examine: 1 . the discrepancies between patients and caregivers in AQ-D clinical factors, and 2. the association between the AQ-D clinical factors, and sociodemographic and clinical characteristics of patients and caregivers.

\section{Methods}

Design and study population

Cross-sectional study using 221 patients and their caregivers from Bellvitge University Hospital were included.

\section{Variables and instruments}

Patients evaluated their cognition and anosognosia level (AQ-D; Migliorelli et al., 1995).

Caregivers evaluated patients’ variables (age, gender, marital status, education, family 


\section{LETTER TO THE EDITOR}

relationship, anosognosia, functionality, depression, neuropsychiatric symptoms and dementia severity) and had caregiver burden, physical and mental health assessed.

\section{Statistical analysis}

Wilcoxon test determined the differences between caregivers and patients' AQ-D scores and Cohen's $d$ measured the effect size in these differences. Spearman's correlations explored the relationship between AQ-D and patients and caregivers’ variables.

A principal components analysis for the AQ-D was carried out with rotation (varimax). To verify clinical perspective, the researchers grouped the 30 items of the AQ-D on three factors. Variance and Cronbach's alpha for each factor estimated contribution and internal consistency. Two multiple linear regression analyses were performed to determine the influence of the independent variables on existence of anosognosia.

The level of significance for comparisons was $\mathrm{p}<0.05$. SPSS v22.0 for Windows (SPSS Inc., Chicago) was used to statistical analysis.

\section{Results}

Most patients were females (63.3\%), with mean age of $77.8 \pm 6.3$ years, with formal education > five years (36.7\%), and with a mean MMSE score of $18.3 \pm 5.4$.

Cronbach's alpha was high ( $\alpha=0.91)$, indicating excellent internal consistency. Three factors were grouped: 1 Cognition, 2 Functionality, and 3 Behaviour/Personality. In the multivariate analysis, to patients, the factor Functionality was the most relevant in the association between high levels of anosognosia and deficits in activities of daily living (ADLs) $(p<0.001)$, less depressive symptoms $(p<0.001)$, more neuropsychiatric symptoms $(p<0.001)$, and older patients $(p=0.012)$. To caregivers, the factor Personality was the most 


\section{LETTER TO THE EDITOR}

important in the relationship between high levels of anosognosia and caregiver burden $(p<$ $0.001)$ and female gender $(p=0.022)$.

\section{Discussion}

Factor 1 Cognition presented high Cronbach’s alpha ( $\alpha=0.84$ ), indicating good to excellent internal consistency of the scale. Cronbach's alpha was moderate in Factor 2 Functionality ( $\alpha$ $=0.77)$, and Factor 3 Behaviour/Personality $(\alpha=0.70)$. Our results may suggest a relative independence between anosognosia levels for different abilities (Starkstein et al., 2006).

The highest discrepancy between patients and caregivers in AQ-D clinical factors occurred in factor 1 Cognition. Correa et al. (1996) indicated that AD patients showed anosognosia of the severity of their memory decline on a questionnaire and made fewer selfcorrections.

AQ-D clinical factor varied according to the rater in the present study, to patients was factor 2 Functionality that was influenced by deficits in ADLs. This finding deserves attention, because functionality scores predicted the scores for the domains of anosognosia of functional deficits on the AQ-D clinical factor (Starkstein et al., 2006). Likewise, another consensus in literature is a higher frequency of neuropsychiatric symptoms in the anosognosia, and our study is in line with this finding (Conde-Sala et al., 2015). Furthermore, we suggested that less depressive symptoms in patients with AD were associated with high levels of anosognosia. The presence of low levels of depression may mean non-awareness of deficits (Portellano-Ortiz et al., 2014). While to caregivers, the factor was 3

Behaviour/Personality. Higher discrepancies of anosognosia between patients and caregivers have been mostly correlated with neuropsychiatric symptoms. Moreover, the presence of more neuropsychiatric symptoms and anosognosia were related to caregiver burden (CondeSala et al., 2015). 


\section{LETTER TO THE EDITOR}

Finally, our findings indicated that in a clinical perspective, the grouping of AQ-D items on three factors Cognition, Functionality and Behaviour/Personality was consistent. Also, we confirmed that anosognosia is multidimensional phenomenon that it is in agreement with AD diagnostic criteria.

\section{Conflict of interest}

None declared.

\section{Acknowledgements}

This study was conducted within the framework of the project Assessing perceptions of patient quality of life in patients with Alzheimer's disease and their family caregivers over a two-year period, funded by Spain’s Ministry of Economy and Competitiveness (reference PSI2010-19014), IP: Conde-Sala JL. This research in Brazil was supported by the Conselho Nacional de Pesquisa (CNPq). 


\section{LETTER TO THE EDITOR}

\section{References}

Conde-Sala JL, Turró-Garriga O, Piñán-Hernández S, et al. 2015. Effects of anosognosia and neuropsychiatric symptoms on the quality of life of patients with Alzheimer's disease: a 24-month follow-up study. doi: 10.1002/gps.4298.

Correa DD, Graves RE, Costa L. 1996. Awareness of memory deficit in Alzheimer's patients and memory-impaired older adults. Aging Neuropsychol Cogn 3: 215-228. doi: $10.1080 / 13825589608256625$

Migliorelli R, Tesón A, Sabe L, et al. 1995. Anosognosia in Alzheimer’s disease: a study of associated factors. J Neuropsychiatry Clin Neurosci 7(3): 338-344. doi: dx.doi.org/10.1176/jnp.7.3.338

Portellano-Ortiz C, Turró-Garriga O, Gascón-Bayarri J, et al. 2014. Anosognosia y depresión en la percepción de la calidad de vida de los pacientes con la enfermedad de Alzheimer. Evolución a los 12 meses. Rev Neurol 59(5): 193-204.

Starkstein SE, Jorge R, Mizrahi R, Robinson RG. 2006. A diagnostic formulation for anosognosia in Alzheimer's disease. J Neurol Neurosurg Psychiatry 77(6): 719-725. doi: 10.1136/jnnp.2005.085373 


\section{LETTER TO THE EDITOR}

Table 1 Multivariate Linear Regression Analysis: AQ-D clinical factors and patients and caregivers’ variables

\begin{tabular}{|c|c|c|c|c|c|c|c|c|c|c|c|c|c|}
\hline \multirow[b]{2}{*}{ Patients } & \multirow[b]{2}{*}{$\mathrm{R}^{2}$} & \multicolumn{3}{|c|}{ DAD } & \multicolumn{3}{|c|}{ NPI } & \multicolumn{3}{|c|}{ GDS-d } & \multicolumn{3}{|c|}{ Age } \\
\hline & & $\beta$ & $t$ & $p$ & $\beta$ & $t$ & $p$ & $\beta$ & $t$ & $p$ & $\beta$ & $t$ & $p$ \\
\hline AQ-D total & 0.666 & -0.51 & -10.9 & $<0.001$ & 0.34 & 7.4 & $<0.001$ & -0.31 & -8.0 & $<0.001$ & 0.09 & 2.4 & 0.014 \\
\hline Factor 1 & 0.559 & -0.51 & -9.5 & $<0.001$ & 0.25 & 4.7 & $<0.001$ & -0.30 & -6.6 & $<0.001$ & 0.10 & 2.2 & 0.023 \\
\hline & & \multicolumn{3}{|c|}{ ZBI } & \multicolumn{3}{|c|}{ Gender (women) } & \multicolumn{3}{|c|}{ Age } & & & \\
\hline Caregivers & $\mathrm{R}^{2}$ & $\beta$ & $t$ & $p$ & $\beta$ & $t$ & $p$ & $\beta$ & $t$ & $p$ & & & \\
\hline AQ-D Total & 0.299 & 0.50 & 8.7 & $<0.001$ & 0.14 & 2.3 & 0.019 & 0.13 & 2.3 & 0.021 & & & \\
\hline
\end{tabular}

Factor 1: Cognition; Factor 2: Functionality; Factor 3: Behaviour/Personality.

$\mathrm{R}^{2}=$ Determination coefficient; $\beta=$ standardized beta coefficient; $t=$ Students $t$, test.

AQ-D: Anosognosia Questionnaire for Dementia; DAD: Disability Assessment for Dementia; NPI: Neuropsychiatric Inventory; GDS-d: Geriatric Depression Scale; ZBI: Zarit Burden Interview. 